\title{
Potential habitability of Mars based thermodynamic models of Martian soil simulants
}

\author{
LAURA FACKRELL ${ }^{1} *$, PAUl A. SCHROEDER ${ }^{2}$ \\ ${ }^{1}$ Geology Department, University of Georgia, Athens, GA \\ 30602 USA (*correspondance: lauraelf@uga.edu) \\ ${ }^{2}$ Geology Department, University of Georgia, Athens, GA \\ 30602 USA (schroe@uga.edu)
}

\section{Introduction}

If the assumption is made that any life on Mars was (or is) comparable to life on Earth then examing the functions of terrestrial organisms using Mars-like soil simulants can help project feasibility for establishing habitallity on Mars. Modern Earth soil microbial populations contain various species that take advantage of energy and nutrient resources using hydrolysis and redox functions such as ion comlex solubilization, carbon fixation/respiration, and nitrification/denitrification [1]. Thermodynamic models using mineral assemblages can be useful to examine the various roles of microbes and inform how nutrient activities might be manifested given affects of metabolic products and reactants [2]. The objective of this study is to explore with thermodynamic models (Geochemist Workbench) to inform hypotheses in support of the habitability of Mars.

Five Martian simulant assemblages were used and include, 1) Global Soil, 2) Phyllosilicate-smectite, 3) Phyllosilicate-illite, 4) Sulfate-rich, and 5) Carbonate-rich [3]. Geochemical models were desgined to parallel plant growth experiments in the above simulants using microbial inoculants as biofertilizers that expose minerals to acids and bioweathering. Cheimcal, mineral, and fertility anlysis measured both total mineral phases and extractable nutrients. This data along with information known from the literature of the specific microorganisms being used as biofertilizers [4-6] were used to constrain parameters in the thermodynamic models in Mars-like soil (though Earth-like atmosphere). This work can be used to inform more robust models that direclty take into account additional aspects of the early Earth and Mars environments (e.g. climate and atmospheric conditions).

\section{References}

[1] Douglas, J. (2005) Amer. Jour. Sci., 305, 503-525. [2] Schock, E.L., et al. (2010) Geochem. Cosmo. Acta, 74, 40054043. [3] Fackrell, L.E., (2018) GSA 2018 Oral Presentation. [4] Thies, J.E., et al. (1991), Appl Env. Micro. 57, 1540-1545. [5] Siddikee, M.A., et al. (2011) Plant Phys and Biochem, 49, 427-434. [6] Tarafdar, J.C. and Rao, A.V. (1997) Symbiosis, $22,265-274$ 